\title{
Improve the Sense of Ecological Environment Protection in the Process of Reconstruction Rural Area in Vietnam - Experience from China
}

\author{
Pham Huy Thong ${ }^{1,2,}$, , Shu Yuan Zhao ${ }^{1}$, Nguyen Thi Thuong ${ }^{3}$, Pham Thanh Trung ${ }^{4}$ \\ ${ }^{1}$ College of Marxism Studies, Hunan University, Changsha City, China \\ ${ }^{2}$ Faculty of Political Theory, Hatinh University, Hatinh City, Vietnam \\ ${ }^{3}$ Faculty of Economy Business Administration, Hatinh University, Hatinh City, Vietnam \\ ${ }^{4}$ Faculty of Political Theory, Hoalu University, Ninhbinh City, Vietnam
}

Email address:

phamhuythong@163.com (P. H. Thong)

*Corresponding author

\section{To cite this article:}

Pham Huy Thong, Shu Yuan Zhao, Nguyen Thi Thuong, Pham Thanh Trung. Improve the Sense of Ecological Environment Protection in the Process of Reconstruction Rural Area in Vietnam - Experience from China. International Journal of Environmental Protection and Policy. Vol. 5, No. 4, 2017, pp. 48-53. doi: 10.11648/j.ijepp.20170504.11

Received: January 21, 2017; Accepted: February 14, 2017; Published: June 2, 2017

\begin{abstract}
Rural Ecological Environmental Pollution in Vietnam is becoming more serious. However, protection of ecological environment in rural areas is inadequate. Therefore, raising awareness of ecological environment protection is one of the key solutions to protect the ecological environment in rural areas in the process of new rural construction in Vietnam today. Besides, Vietnam should adapt experience in protecting the ecological environment from other countries, including China.
\end{abstract}

Keywords: Consciousness, China, Environment, New Rural, Vietnam

\section{Introduction}

In Viet Nam, the new rural construction is a key program of the Resolution No. 26-NQ/TW which has been the most comprehensive resolution on the agriculture development, farmers and rural areas so far. After 6 years of implementation, many rural areas is changing, socioeconomic infrastructure is upgraded, life of most farmers is improved, poverty is reduced. However, compared with the goal of the new rural construction in Vietnam, there are still many issues that need to be addressed to meet the requirements, especially the protection of the ecological environment. Therefore, Vietnam needs to propose right solutions towards the pollution of the ecological environment throughout the innovation of rural areas. In addition, Vietnam should adapt experience in protecting the ecological environment from other countries, including China.

\section{Current Status of Ecological Environment in the Process of Reconstruction Rural Area in Vietnam}

In Vietnam, in recent years, ecological environmental pollution problems are concerns of the whole society, especially the environmental pollution in rural areas which is caused by wastes from daily life, livestock, the abuse of plant protection drugs in agricultural production.

Currently, a lot of places, especially remote areas, are facing to the ecological environment protection. We have never seen wastes from daily life in rural areas as much as now. Wastes such as plastic bags, dead animals are thrown by the people of no sense to all places from the village, hamlet, alleys to canals, lakes, rivers... any places which are convenient and near for them to throw wastes, littering. Meanwhile, environmental sanitation services in rural areas are not developed according to the actual situation. A further 
problem is that most people do not classify wastes, so the landfill, collection and treatment are difficult.

Besides, the problem of loss of rural sanitation now is partly due to large amounts of waste from rural markets. This is the place of all kinds of wastes without any methods of collection and treatment. Now, wastes are mainly treated by gathering to burn or let them decompose naturally. So, it has one heavy impact on the environment in particular and environmental protection in general. Besides, the amount of waste, livestock waste, economic development needs of the people are expanded without any changes in farming methods, most of them follow the old styles; shit, water and the leftovers of livestock and poultry are untreated and released into roads, ditches, rivers, ponds and lakes. When it rains, wastes are smell flow away. When it is sunny, wastes create uncomfortable smell. This is a favorable environment for flies, mosquitoes, the parasites that cause the disease to arise and release into the air and water, waste water seep into groundwater, therefore, the risk of proliferation of diseases is high in the community.

Table 1. The number of people suffering from diseases related to the water environment in Phu Tho province.

\begin{tabular}{lllll}
\hline \multirow{2}{*}{ Disease } & \multicolumn{4}{l}{ Number of people suffering from diseases } \\
\cline { 2 - 5 } & $\mathbf{2 0 0 6}$ & $\mathbf{2 0 0 7}$ & $\mathbf{2 0 0 8}$ & $\mathbf{2 0 0 9}$ \\
\hline Cholera & 0 & 2 & 5 & 0 \\
Typhoid & 0 & 0 & 0 & 0 \\
Dysentery rectum & 88 & 130 & 45 & 59 \\
dysentery amoeba & 12 & 92 & 56 & 56 \\
Dysentery syndrome & 2.936 & 2.812 & 2.660 & 3.042 \\
Diarrhea & 7.748 & 9.230 & 10.437 & 11.462 \\
\hline
\end{tabular}

Source: Vietnam National Environment Report 2015 [13].

In addition, the rural environment is threatened by abuse of agricultural chemicals such as fertilizers, plant protection products and the use of fresh manure, especially in the production of green vegetables. This is very harmful to human health, a serious impact on the environment we are living and for future. According to the national environmental report in 2014: "In the past 30 years, about 40 new diseases have arisen and are derived from environmental pollution. A range of respiratory diseases, intestinal infectious diseases, gynecological diseases... is increasing, environmental factors as disease agents. Some cancer villages, villages of disease have occurred in rural areas. The "incurable" diseases which are often prevalent in urban areas where suffer many toxic chemical now become the risk of the countryside "[11].

\section{China's Experience is to Strengthen the Education of Communication, Raise Awareness of the Environment in the Process of Reconstruction Rural Area}

Like Vietnam, in the process of building new rural areas, the problem of rural environmental pollution in China is also quite severe, mainly manifested in pollution in domestic activities, severely dispersed pollution, increased mining pollution, polluted water sources. Therefore, to promote the growth of rural economy, to improve the environment and the ecological and cultural life in rural areas, since 2003, China has implemented many measures, emphasizing the importance of measures to enhance education and propaganda on the environment and raising people's environmental awareness.

Fist, on environmental education dissemination for leaders

"Leaders at all levels, civil servants, employees of administrative units, especially the leaders, are the focus of environmental education dissemination"[6]. Through education, leaders will understand the state of environmental protection in the country and the dynamics of environmental protection abroad, clearly understand the law on environmental protection, are aware of the concept of scientific development, decision-making on environmental integration and development, actively and proactively solve environmental issues closely relating to the interests of the public.

The current state of the rural environment and the legislation on environmental protection in the rural area in the domestic and foreign areas is the focus of the education and understanding of the relationship between the concept of scientific development and the protection of the environment in the rural areas.

Through notices of state of the environment status, tapes, internal documents, periodic notices to leaders on the status and direction of change of environmental damages and agricultural pollution in specific areas and across the whole country, so that leaders understand the seriousness of ecological damages and environmental pollution and raise awareness of the urgency of environmental protection. Political schools, administrative academies and staff training schools at all levels should include environmental education in the curriculum; Party committees in areas and units should organize seminars on knowledge of environmental protection; implement training programs for civil servants specializing in environmental protection related work, raise environmental protection awareness and enforcement of the environmental law of the environment law enforcement team.

Second, on environmental education dissemination for rural enterprises

Workers and managers of enterprises exploiting natural resources and enterprises with wastes are taken as key objects, and grasp the knowledge and the provisions of the law on environmental protection in each particular profession, understand the requirements and methods of production hygiene, economic circulation, make use of waste of each industry, location.

Focus on enhancing the law on environmental protection in rural areas and the social responsibility education for enterprises, so that enterprises can understand the importance and the environment protection are the social responsibilities which can not be ignored, deploy the production model of hygiene, build the images of green enterprises.

Towards propagandizing to enterprise leaders about the 
concept of scientific development and strategic thinking for sustainable development, recognizing the current status and trends of rural pollution, identifying environmental responsibility of the enterprises, promoting the transformation of economic development modalities, promoting the prevention of pollution; revolving around the need to follow the path of new industrialization, organizing various types of seminars and training courses in line with the reality, and popularizing knowledge and skills in environmental protection. For the implementation of environmental education for all employees in enterprises which are often polluted, control the origin of pollution, promote clean production, build green enterprises; For production units seriously affecting the environment, provide vocational training to employees. For workshops, key production stages in the enterprises with waste, conduct the environmental education and training degree; Promote the effectiveness of monitoring of communication, timely reporte and praise examples of environmental protection, publicly expose and criminalize violations destroying the environment, form a social lifestyle with the slogan "environmental protection is glorious, environmental damage is shameless."

Third, on environmental education dissemination for the public

Get qualified labor forces such as: farmers, village officers and households who apply advanced production technologies, civilized households, clean food producers, professional production households, households cultivating food crops and collective of the Party Committee as the focus of environmental education. Help the public grasp basic knowledge of environmental protection, understand the basic requirements of environmental protection in agriculture, and grasp basic methods of eco-development in agriculture, foster and train key agricultural households which have been exposed to environmental education as eco-farming households; foster new-type farmers who are cultured, technically skilled, know how to do business, love the environment, promote the construction of a new socialist rural area; lead farmers step by step to form the way of living and civilized and scientific production, foster awareness of maintaining environmental benefits.

The focus is on the implementation of education on the use of science and technology, especially the use of chemical products in agriculture, so that farmers can grasp the relationship between scientific farming and the protection of rural environment.

Around the production of science and the increase of productivity, efficiency of production, in combination with the propaganda in use of technical measures in agricultural production and improving the ethical quality of the environment of farmers, stimulating the majority of farmers actively participate in environmental protection; combining training activities such as "green certification work", "women enrich with science and technology", implementing programs to foster farmers in environmental protection in a spear practical effect, simple and easy to understand; promoting well the effect of educational units such as rural television schools, cultural and technical fostering schools for rural adults, rural technological enrichment universities, and thorough agricultural technology education and combination of websites, relevant universities and secondary schools and etc in fostering environmental protection in rural areas; Carrying out the activities of "environmental education and propagation to the rural areas", promoting effective ways and methods such as creating conditions for employees to master science and technology on environmental import protection, blue in the village flourishing and etc, finding out long-term mechanism for asking people's questions about issues relating to environmental protection; Continuing to organize the implementation of the "popularization of environmental protection science in rural areas", carrying out popularization activities of environmental protection science in villages such as the week of science and technology, scientific popularization date and etc printing handbooks for dissemination of environmental protection science, propaganda pictures for localities, and posting propaganda images at the most important positions in the Committees and schools in villages; Utilizing the contents, images and forms of entertainment that people like, such as broadcasting, television, film, picture books, communication brochures, and entertainment programs and etc, announcing knowledge of environmental protection, the transmission of wealth information in the green forms, the propaganda combined with poverty reduction and hunger elimination, encouraging the majority of people voluntarily participate in environmental protection; taking advantage of the "Tam Ha Huong" summer program, organizing university students to play role as officers and farmers to conduct discussions on environmental science popularization, communication materials to improve the knowledge of the majority of people about environmental protection.

Fourth, on environmental education dissemination for pupils and students

To get students, pupils from the primary schools to universities as the focus, propagate the concept of scientific development, popularize scientific and legal knowledge in the field of environmental protection. In order that students, pupils form the habit of protecting the environment, close and enjoy the nature. Strengthen the legal notion and environmental consciousness of undergraduate students, require that students enrolled in environmental related majors to master how to prevent pollution in agricultural production and the basic rehabilitation skills.

Disseminate the country's basic situation such as abundant population, limited resources, and the relationship between people and the nature, grasp the methods and skills of environmental protection in the rural areas.

Implement "green school" construction, incorporate environmental education into the teaching and testing system in "green schools"; implement environmental education, incorporate environmental education into the syllabus of teaching elementary and secondary schools, and promote environmental education in the most comprehensive manner. 
Promote environmental education for pre-school children, develop teaching on environmental curriculum in an integrated manner, allocate responsibilities at specific stages, put environmental education in the curriculum of natural and geographic subjects and etc, make periodic environmental education quality inspection; Incorporate environmental education resources outside the schools, build a practice area for environmental protection activities outside the schools with a mechanism to operate effectively, close to the curriculum in the schools. Utilize a variety of educational resources from places where science and technology is popularized, such as science and technology museums, research institutes, and places for environmental protection education for young people, serve the moral improvement of the protection of the environment of minors; Enhance the environmental education function in off-campus youth-based organizations such as center of children activities and youth cultural center and etc, promote the educational effect of wards on off-school environmental education for adolescents; Enhance development of science and technology in the environmental majors, create the achievements and talents in the field of environmental protection. Encourage students to participate in innovative environmental research, actively introduce and promote achievements in environmental protection; Incorporate major anniversaries such as World Environment Day, Earth Day and etc, launch environmental education activities with clear themes and diverse forms, make environmental culture a part of the environment. Make environmental culture become an important composition in school culture, contributing to the clean campus; Universities at all levels may, based on the actual situation, incorporate environmental protection into the teaching system, encourage students to carry out "environmental protection in the rural areas", investigate the current state of the environment, enhance students' awareness of environmental issues.

\section{Solutions to Improve the Sense of Ecological Environment Protection in the Process of Reconstruction Rural Area in Vietnam}

Lack of understanding of the ecological environment is one of the main causes of the ecological environment pollution in the process of new rural construction. Lacks of understanding means that people have little knowledge of the ecological environment, they do not realize the role and importance of the protection of the ecological environment in rural areas. Simultaneously, lack of understanding about ecological environment shall make people fail to protect ecological environment, they shall release waste to rural ecological environment without knowing its consequences. Moreover, they also failed to produce effective solutions to protect and improve the ecological environment in rural areas. So, the awareness of protecting the ecological environment in rural areas should be raised by adapting China's experience in dealing with the pollution of the ecological environment during the innovation of rural areas, Vietnam need to implement some solutions as follows:

First, it needs to raise the awareness and responsibility of protecting the ecological environment of the leaders. Protection of rural ecological environment is the responsibility of the whole society, but first and foremost is the responsibility of the State. So, first of all, it needs to strengthen education to raise awareness and action to protect rural ecological environment in the party committees, governments, Fatherland Front and mass organizations and the people. In particular, it need to focus on training staff from the central leadership to the leadership in the provinces, districts, towns and communes so that they have the knowledge of the ecological environment. They are the nucleus of the operational system of ecological environment. To do this, it needs to organize training courses on sustainable development, the relationship between humans and the ecological environment, the relationship between the ecological environment and rural development for the leaders. In addition to changing the thought of the leaders on the protection of ecological environment in rural areas, it should have clearly defined terms on protection of rural ecological environment of the leaders. For example, leaders of ministries shall be responsible for the occurrence of pollution in their local environment and in ministries and branches they managed without timely treatment measures. It needs to consider the direction and execution of law on rural ecological environment protection as one of the indicators of emulation and commendation, promotion of leading cadres of the ministries, branches and localities.

Second, it needs to raise awareness of the responsibility to protect rural ecological environment for businesses. Reality in the past shows that most of the violations of environmental protection laws in rural areas are due to the businesses. Enterprises have taken advantage of the gap of the law to discharge wastes into the environment without treatment. On the other hand, enterprises are not aware of their role for the protection of ecological environment in rural areas, so they are the forces contributing to environmental pollution and fast recession in rural areas. To change the perception, attitude and behavior of many enterprises in protection of rural ecological environment, following measures should be implemented:

Organizing training courses to raise awareness about social responsibility of the enterprises to the environment according to each target group. For example, for enterprise leaders such as Board of Management, Board of Directors should focus on raising awareness of green growth, social responsibility of the enterprise, overall economic benefits from investing in protection of rural ecological environment. For officials who are responsible for protection of the rural ecological environment, the contents of the training courses should focus on establishment of internal environmental management system; clean production projects, calculation of costs - benefits of clean production.

Develop strongly networks of centers on clean technology promotion \& training and cleaner production to support 
businesses. Especially, it needs to organize activities to raise awareness of businesses about the economic benefits from investment projects in clean technology or clean production which is cheaper than the investment projects in controlling pollution in all businesses.

Organizing propaganda, commend and reward businesses which strictly complied with provisions on the protection of ecological environment in rural areas; labeling environmentally friendly products for products of energy saving and natural resources saving.

Publicizing information on the situation of pollution and compliance with the law on the protection of the ecological environment of the rural areas of business which are relating to the people, social organizations, consumer, the investors to put pressure on businesses, forcing businesses to implement measures to protect rural ecological environment.

Developing the monitoring mechanisms of people and community towards enterprises in implementation of environmental commitments and regular maintenance of measures to reduce environmental pollution; Forming communication channels between citizens and local authorities to promptly inform about the cases of violation of rural ecological environmental protection laws.

Institutionalization of the regulations on social responsibility of enterprises for environmental protection. Accordingly, it needs to issue government Decrees on the social responsibility of enterprises in the economic development process. At the same time, the government should promulgate policies to encourage enterprises to adopt clean production, especially to encourage small and medium enterprises in the villages to contribute capital to invest in pollution treatment system in the combination between the State and Businesses.

Third, promoting the spirit of the farmer, owner of the whole society in the protection of ecological environment. The protection of rural ecological environment in new rural construction needs contribution of many people at many levels, industries. However, farmers are direct performers and decide the success of implementation. They are absorbing technological advancements and are directly selecting technologies, techniques applied to production, directly absorbing mechanisms, policies, market access and turning potentials into reality. However, the reality of rural in Vietnam today shows that most farmers are not aware of the environmental problems of rural ecology. So, they have violations of environmental protection laws which they do not know too. Most of the regulations on environmental protection are only expressed in writing without going into life. Many farmers did not know their rights and obligations in the protection of ecological environment in rural areas. To enhance their role in protecting ecological environment in rural areas, the State must strengthen education, advocacy, guidelines, policies and legal system for environmental protection to each citizen, raising the level and competence of mastery of farmers in protecting ecological environment in rural areas.

To do this, the State should have a plan to diversify the forms of education and communication on rural ecological environmental protection in agricultural production for farmers, organizing many training courses on ecological environment protection in the rural areas of agricultural production as well as in animal husbandry, propagandize environmental protection laws to every rural household. For households of large production and farming, the State should guide them to implement commitments to rural ecological environment protection, guiding them on clean production based on agricultural innovation as well as the restoration of contaminated lands. In the long term, the State should focus on youth- the future owners of the countryside in particular and the country in general. It needs to integrate ecoenvironmental education into the education system at all levels of education in the national education system and maintain them regularly to establish the awareness of rural ecological environment protection of each student from which to form self-consciousness in rural ecological environment protection. It needs to build, invest in the programs, topics on environment on media such as radio and television stations at all levels, press and other mass media.

Schools and families are the most appropriate places for education one ecological environmental education. Especially in rural areas, environmental education should start from the family. Here, the role of the mother is very important because in rural area of Vietnam, women are the main workers of natural resources such as farming, logging, and farming.

To make knowledge about the ecological environment gradually penetrates deep into the people's selfconsciousness, it needs to expand and strengthen the communication activities, environmental supporters. For example, the organization of the contest to learn about the environment, cultural and artistic movements with contents associated with the protection of the ecological environment in rural areas on the occasion of World Environment Day, Day of clean water and environmental sanitation, Day to make the world cleaner, Day of biodiversity...

To create opportunities and conditions for people to access regularly with information on the environment, helping rural ecological environment protection become more proactive, efficient, the State should also encourage and guide people to form environment friendly lifestyle, clean living with good sense of public hygiene, rational production and consumption, not polluting the ecological environment, building a civilized consuming culture, saving, antiextravagant, wasteful habit, environmentally harmonious and friendly lifestyle. The State needs to push the movements, union activities in protecting rural ecological environment such as the green - clean - beautiful movements, or weeks of clean water and environmental sanitation... After each launch, it needs to review, evaluate, reward to encourage and mobilize the units and individuals of outstanding achievements in the movements and remind weak units or individuals; Performing construction and application of environmental criteria in the emulation and commendation of the units and individuals; publicizing the violations of 
environmental law on the mass media.

Through the public unions and community activities, organizing propaganda and education to raise awareness of farmers on sustainable development with ecological ethics education because in rural ecological environmental protection, three tools of economics, law and ethics are inextricably linked to together in regulating human behavior. Ecological ethics is an aspect of ethics in general, an expression and manifestation of social ethics in the relationship between humans and the environment. It needs to build ecological ethics because behind the relationship between humans and the environment is the ethical relationship between people. Especially in rural areas, people are very respectful ethics. So, to protect the ecological environment in rural areas, law is not enough. Ecological ethics education for farmers have big role and is indispensable in regulating human behavior on the environment.

In the ecological ethics education for farmers and people in society, the State should integrate it with the need for ecological environment protection of Marxism - Leninism and Ho Chi Minh's Ideology with the philosophy of "heavenly consolidation "of the East in order to build an ecoethical standard in accordance with the people of Vietnam. Therefore, we should actively exploit the traditional humane values in protecting t ecological environment of the people in rural of Vietnam. Historical practice has shown that Vietnamese have many experiences of effective ecological environment protection in rural areas. However, nowadays, due to many reasons such as poverty, the impact of market mechanisms, the increase in the population..., Vietnamese have forgotten or abandoned the good practices of environment protection. Therefore, the State should actively research, evaluate and summarize lessons learned from among the people on ecological environment protection.

\section{Conclusion}

From the experience of protecting the ecological environment throughout the innovation of rural areas in China, it is obvious that there exists insufficient and shallow recognition of economic development and the protection of the ecological environment in Vietnam. Therefore, the people should have proper awareness to have proper actions in protection of ecological environment in rural areas. If there is adequate investment with thoroughly implementation to raise the awareness of people about ecological environment protection in rural areas, it will create a significant shift in thinking and way of life of the people. From there, they will be a big change in action. Once they are aware of rural ecological environment protection, it shall become selfconsciousness of every citizen in the process of new rural construction. This solution is built on the basic principles of Marxism - Leninism: the people is both the actors and the product of society and the conscious control of the relationship between humans and environment.

\section{References}

[1] Dan. Xuan. To., Vien. Van. Le., Hung. Trong. Do., [2013], the new rural area development in Vietnam: New Vision, New Management Organization, a new step, Agriculture Publishing House, Hanoi.

[2] Duyet, P, [2011], Adjust and change foreign economic strategy of China's foreign policy in the post financial- currency crisis period, Institute for Strategic Studies Foreign Policy. China Central Party School.

[3] Environmental Protection Act and its implementing decree [2005], National Political Publishing House, Hanoi.

[4] Greenpeace, [2014], Annual reports about how-is-greenpeacestructured. [Online] Available:

$\mathrm{http}: / / w w w . g r e e n p e a c e . o r g /$ international/en/about/how-isgreenpeace-structured/reports/.

[5] Hoa, V. Trac., [2000], China- serious challenges of the new century, China Social Science Publisher.

[6] Hua Ming, Chen Run Yang, Hua Qi He, [2014], The socialis new rural reconstruction: challengers and strategies of environmental protection, Beijing, China environmental publishing house.

[7] International conventions on environmental protection [1995], Hanoi, Vietnam: National Political Publisher.

[8] Lu Yuan $\mathrm{Ru}$ (2014), Harmonious development of economic development and environment protection in the construction of new rural areas, China economic publishing house.

[9] Marx, H. K., and Engels, F, [2002], Full episode, episode 20, National Political Publisher, Hanoi, Vietnam, Pg 477-644-652654-720.

[10] Marx, H. K., [2002], The economic-philosophical draft 1844, Hanoi, Vietnam: Truth Publisher.

[11] Pham Huy Thong, Pham Thanh Trung, Nguyen Thi Thuong, [2016], philosophy basis of relationship between environmental protection and transformation of economic development method in developing countries, International Journal of Recent Scientific Research, Volume: 7 (4) April 2016, pg 10643-10647.

[12] Ryle, H., and Martin M, [1998], Ecology and Socialism, London: Radius.

[13] The Ministry of Natural Resources and Environment, [2015], the National Environment Report 2015.

[14] Vietnam's Ministry of Agriculture and Rural Development National Conference summary 2010-2015 five-year phase of new rural construction of the national target program implementation [2015].

[15] UNDP [2006], Human Development Report. New York: UNDP.

[16] UNEP [2011], Towards a green economy, roadmap for sustainable development and poverty reduction. Summary report serving policy makers. Viet Nam: Agriculture Publisher. 